\title{
Developing An Economic Partnership Framework Between The Lheidli T'enneh First Nation And Initiatives Prince George Development Corporation
}

Franca Petrucci, Northern Health Authority, Canada

Rick Tallman, University of Northern British Columbia, Canada

\begin{abstract}
Both non-aboriginal corporations and First Nation bands are recognizing the benefits of forming economic partnerships. Each First Nation is unique and economic partnerships have to be designed to fit the partners' capabilities. The purpose of this paper is to discuss the development of a framework for an economic partnership between the Lheidli T'enneh First Nation and the Initiatives Prince George Development Corporation. This framework was intended to offer structure, engagement, and guidance to that partnership. The economic development framework was created by a committee composed of representatives from the two parties with one of the authors acting as the facilitator. The committee identified nine elements that were deemed important to their relationship. It expanded on each of these elements under the headings of "our definition", "strategic actions" and "performance measures". The framework developed by the committee is intended for the Lheidli T'enneh First Nation and the Initiatives Prince George Development Corporation but can serve as a guide for other parties.
\end{abstract}

Keywords: First Nations; Economic Development; Framework; Partnership; Agreement

\section{INTRODUCTION}

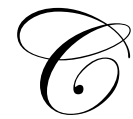

orporate and Aboriginal partnerships in economic development are growing in Canada. Non-Aboriginal corporations are developing business alliances with Aboriginal peoples as a part of their strategy for long-term corporate survival (Anderson, 1997). Business ventures in northern British Columbia recognize successful Aboriginal engagement, capacity building, and partnership as a key priority for economic development and diversification. As well, many First Nations are aligned with this priority as they recognize the social, political, and economic advantage in partnering with non-Aboriginal business ventures (Whyte, 2006, p. 3).

Economic development issues facing First Nations are extremely diverse and very complex. Shanks (2005) notes that any public policy or program response will have to be custom made to fit a variety of circumstances. First Nations communities are unique and they are at various stages in terms of their capacity to plan for and seek appropriate economic activity. Even though there are some similarities, each First Nation's culture has distinct characteristics such as, cultural practices, beliefs, languages, governing structures, decision-making systems, communication processes, and politics (British Columbia Ministry of Economic Development (BCMED), 2007). In addition, each First Nation community is in different stages of attaining self-government, economic development, and/or successful treaty negotiations. These are important issues that must be attended to in developing an economic framework for a partnership between a Fist Nation band and a non-Aboriginal corporation.

The purpose of this paper is to discuss the development of a framework for an economic partnership between the Lheidli T'enneh First Nation (LTFN) and the Initiatives Prince George Development Corporation (IPG). This framework was intended to offer structure, engagement, and guidance to that partnership and to future ventures between the two partners 


\section{LITERATURE REVIEW}

\section{Partnership Typology}

Brinkerhoff (2002), defines the dimensions of partnership as encompassing mutuality and organization identity. Mutuality refers to the mutual dependence of each partner on the other and it entails respective rights and responsibilities. Organizational identity refers to that which is unique and differentiates itself from other organizations. Organizational identity is the reason for selecting a particular partner (Birkerhoff, 2002).

Partnerships can be categorized according to a range of characteristics that identify specific dimensions or activities in various types of partnering arrangements. These broad categories are useful both in categorizing classes of partnerships and also for understanding a particular partnership arrangement. The four types of partnerships, as derived from the literature, are the collaborative, operational, contributory, and consultative types (Kernaghan, 1993; McQuaid, 2000; Rodal \& Mulder, 1993; Wright \& Rodal, 1993). The form of partnership that this project focused upon was the collaborative partnership.

The collaborative partnership involves active power sharing where each partner forfeits a certain level of autonomy. This allows the partners to share equal power in the decision making process. In such a partnership, the partners aim more towards working together in performing various roles and responsibilities. Moreover, there is a tendency towards the pooling of resources. As Brinkerhoff (2002) maintains, collaborative partnerships exhibit 'mutuality'. Proponents tend to choose collaborative type partnerships when the challenges they face cannot be solved alone; this is a benefit of being mutually dependent (Kernaghan, 1993).

\section{Partnership Key Success Factors}

Partnership theory, as discussed in the literature, identifies a variety of factors that are key to successful Partnerships. The five most cited key factors discussed in the literature on partnership theory are to: 1) identify key goals and objectives (Armstrong \& Lenihan, 1999; Brinkerhoff, 2002; Hailey, 2000; Huxham \& Vangen, 2000; Kernaghan, 1993; McQuaid, 2000), 2) build effective relations (Armstrong \& Lenihan, 1999; Brinkerhoff, 2002; Hailey, 2000; Huxham \& Vangen, 2000; Kernaghan, 1993; McQuaid, 2000), 3) clarify roles and responsibilities (Brinkerhoff, 2002; Hailey, 2000; Huxham \& Vangen, 2000; McQuaid, 2000), 4) share resources (Hailey, 2000; Huxham \& Vangen, 2000; Kernaghan, 1993; McQuaid, 2000), and 5) management of the partnership (Armstrong \& Lenihan, 1999; Brinkerhoff, 2002; Huxham \& Vangen, 2000; McQuaid, 2000).

Identify key goals and objectives. Clear goals and objectives ensure that partnerships are driven by a mutual understanding of their vision, purpose, and objectives, as well as, what is to be accomplished. Clear goals offer guidance and clarity, which, in turn, make it easier for partners to work collaboratively. This clarity also offers an environment where the partners can raise sensitive issues about each other's role and performance according to the stated goals and objectives (Hailey, 2000). Clear goals reinforce the purpose of the partnerships, which helps guide the partners through all aspects of the relationship.

Build effective relations. Mutual confidence, trust, and commitment are fundamental to successful partner relations (Armstrong, 1999). If partners are serious about achieving success, they have to be prepared to nurture their relationship (Huxham \& Vangen, 2000). Therefore, partners need to develop a strong willingness to be transparent and work together, which builds trust and strong personal relations.

Clarify roles, responsibilities and expectations. An important component of successful partnerships involves the development of a solid framework based on clarity of roles, responsibilities, and expectations. Therefore, it is important to establish a procedure early in the life of the partnership that identifies distinct roles and responsibilities for those roles.

Share resources. Partnerships are more successful when each of the partners have independent access to resources, as well as when they share those resources for the good of the partnership. The pooling of resources in a collaborative partnership has a synergistic effect in that the collective strength will be greater than the sum of the 
efforts of each partners acting independently (Kernaghan, 1993). In addition to increasing the pool of available resources, partnerships may bring in different types of resources such as information, expertise, and connections with other stakeholders which would otherwise not be available or accessible to the other partner (McQuaid, 2000).

Management of the partnership. Management of partnerships is a multi-facet issue. Three reoccurring themes in the literature regarding the successful management of partnerships are power sharing, accountability, and responsibility. Partnerships may be mutually established, however, the participants of the partnership will each have different reasons for committing to the partnership. In turn, they each bring different resources, skills, and expertise that provide advantages to the partnership. However, managing these differences is likely to be a difficult task. The success of this task will rely on the management of the partnership (Huxham et al., 2000).

\section{First Nation Economic Development Best Practices}

The six most cited key factors to successful First Nation economic development best practices and, therefore, used as the basis to develop the partnership framework were: 1) value in the partnership for both parties (Davies, 2007; Making the Grade, 2006); 2) clear objectives and expectations (Davies, 2007; Whyte, 2006); 3) First Nations business acumen, capacity, and readiness (BCMED, 2007; Hickey et al., 2005; Davies, 2007; and Whyte, 2006); 4) separate politics from business (BCMED, 2007; Hickey et al., 2005; and Curry et al., 2008); 5) shared long-term vision that is inclusive of all members (BCMED, 2007; and Hickey et al., 2005); and 6) build relationships (Hickey et al., 2005; Whyte, 2006; Davies, 2007). As the factors setting clear objectives and expectations and building relationships are discussed above under partnership theory, they are not discussed further.

Shared Value. Successful economic ventures should have a sense of shared value that is supported by ongoing commitment from the partners (Davies, 2007). Partnering involves mutuality where both partners feel they have something to gain and contribute to the partnership (Brinkerhoff, 2002). Aboriginal and non-Aboriginal partnerships offer advantages to each participant of the partnership.

When clearly articulated, shared value give meaning and purpose to the venture. Aboriginal community members grow to appreciate the role of business when they see unemployment levels drop, community programs and infrastructure strengthened and their values respected in the process. Similarly, corporations succeed in engaging their organizations when the business case is strong and tied directly to its overall business objectives (Whyte, 2006, p. 38).

First Nations business acumen, capacity, and readiness. Understanding of a First Nation's business acumen, capacity and readiness to undertake an economic development partnership is one of the key factors in a partnership framework. Capacity building is new to First Nations peoples even though different First Nation communities maintained different levels of capacity (Whyte, 2006). Capacity development is a mutual process of growth and education in order to achieve success between partners (Hickey, 2005).

Separate politics from business. There is a need for stability in First Nations governance as political strife and frequent elections tended to interfere with economic development (Hickey, 2005; BCMED, 2007; Curry, 2008). Working with First Nations individuals or development corporations was more beneficial than working with Band Councils (Curry et al., 2008; Hickey, 2005). However, separating politics from business was often a difficult task (Shank, 2005). Mitigating the problem can be achieved by implementing checks and balances for accountability, engaging and including the community members in a shared vision, articulating clear objectives and expectations, and by identifying governance issues (Shank, 2005; BCMED, 2007).

Shared long-term vision that is inclusive of all members. Partnerships between First Nations and non-First Nations requires acceptance by the First Nation community (BCMED, 2007; and Hickey et al., 2005). First Nations communities must see the partnership as bringing about economic benefits that increase their members' standard of living without sacrificing their cultural values. Each First Nation needs to develop its own long-term vision in conjunction with all members of the community. 
From the above discussion, the following hypothesis guided the partnership between the Lheidli T'enneh First Nation and the Initiatives Prince George Development Corporation:

Hypothesis: For the partnership between LTFN and IPG to be successful, a formal agreement was required based on the factors of identify key goals and objectives, build effective relations, clarify roles and responsibilities, share resources, management of the partnership, shared value, First Nations business acumen, capacity, and readiness, separate politics from business, and shared long-term vision that is inclusive of all members.

\section{METHODOLOGY}

\section{Participants}

The participants of this study were the members of the steering committee struck by the LTFN and IPG. There were two LTFN representatives and three IPG representatives on this committee. One of the authors acted as the facilitator of the committee.

\section{The Process}

The steering committee was tasked with developing and implementing an economic partnership framework between the parties. The committee met once per month to develop an economic partnership framework based on the nine factors identified in the literature review. At the first steering committee meeting, time was allotted for the committee members to develop a vision that would guide the process and the eventual partnership framework. Also at the first meeting, all members had to identify their roles, responsibilities and expectations. One meeting was devoted to defining over twenty key terms and what they meant to the partners. This clarification was important when discussing ambiguous terms such as transparency, accountability, respect, and consultation. Five meetings of the Steering committee were devoted to developing the actual partnership framework. Participants brainstormed strategies that would support the success of each of the nine key factors being utilized for the partnership agreement. Each factor required discussion and agreement on what it meant to the partners, identifying strategic actions and a performance measure that would evaluate the extent to which that key factor was being achieved.

\section{RESULTS}

The text of the partnership framework is divided into the nine key factors that lead to successful partnerships. In each of the nine sections, the factors were discussed individually by the committee in terms of a definition, the strategic actions that need to be taken to ensure implementation, and the performance measures which will be used to evaluate the partnership framework on an ongoing basis. The following results report the framework that was developed by the steering committee.

In the original document, the statements were shown as bullet points using a mix of sentences and action statements. In order to preserve space, the bullets have been removed and the statements reorganized into paragraphs. The original wording in the partnership framework as signed by the two parties is reported here despite the fact that many of the statements are not complete sentences. We felt it was important to preserve the wording of the original document.

\section{Build Effective Partnering Relations}

Our definition. To build a relationship between the LTFN and IPG to build trust, transparency, and mutual confidence amongst the partners. Where mutual trust and reciprocity exists it is much easier to negotiate issues, resolve problems and work towards a common goal. Building an effective relationship allows partners to have some flexibility in their approach, or the way they allocate resources, because of their trust in their partners' reliability and the integrity of their decision-making processes.

Strategic actions. Participate in a one-day workshop to develop a detailed work plan for implementation under the partnership framework. Where deemed appropriate to economic development, IPG will invite LTFN to participate 
in relevant task forces/committees. Where deemed appropriate to economic development, LTFN will invite IPG to participate in relevant task forces/committees. Attend each partners' Annual General Meeting. In the spirit of developing and enhancing effective relations, both agencies will invite partners to organized social events. Establish links to each partner's website on their home website, identifying each other as an economic partner. Upon approval, a representative from LTFN will serve on the Initiative Prince George Board, as a non-voting member. Upon approval, a representative from Initiative Prince George will serve on the LTFN Limited Partnership Board as a non-voting member.

Performance measures. The work-plan from the one-day workshop will be developed and approved by August 2009. The steering committee will meet at minimum three (3) times in 2009. Members from the steering committee will invite and participate in partner's social events and task force/committees, at minimum four (4) times in 2009. Attend each partners Annual General Meetings as an economic partner. Linkage through websites implemented by June 2009.

\section{Shared Goals and Objectives}

Our definition. Clear goals and objectives ensure that a mutual understanding of the vision, purpose, and objectives of the partnership drive the partnership. This enables LTFN and IPG to understand what the expectation is of the partnership agreement and how to work together to accomplish this. These clear goals offer opportunities for mutual agreement and reinforce the purpose of the partnership and help guide the partners through all aspects of the relationship.

Strategic Action. Each partner will identify existing organizational goals and objectives within the parameters of this partnership agreement as the basis of developing mutually compatible goals and objectives under this framework. Commitment from both partners to attend all meetings, task force involvement and social events. Each partner will be responsible to acquire support from their respective governance, and when necessary advocate for the partnership agreement. The steering committee will meet quarterly or more frequently as required to review and participate in assessing economic opportunities, proposals and requests. Review the partnership framework annually to ensure it still meets the goals and objectives of each partner. When economic opportunities are presented, where appropriate, the partners will meet collaboratively with potential customers, conveying a sense of efficiency and organization.

Performance measures. At the one-day implementation workshop the steering committee will identify and record the goals and objectives of this partnership. Members of the steering committee will show their commitment to the partnership by attending $90 \%$ of the steering committee meetings, task force involvement and social events they are invited to. By the second steering committee meeting, partners will have received support for the identified goals and objectives of the partnership, from their respective governance. At the beginning of each calendar year, the goals and objectives of this partnership framework will be reviewed and assessed, to ensure it still meets the needs of each partner. Appropriate budgets for both partners will identify staff and financial resources required to meet these performance measures.

\section{Shared vision of roles, responsibilities and expectations}

Our definition. Develop a solid framework based on clarity of roles, responsibilities, and expectations. This allows for mutual understanding, accountability and ensures a process of transparency in terms of determining who is responsible for what. Establish a clear understanding of definitions of terms that affect the partnership framework to ensure partners are of the same understanding. Build open communication, trust, and respect, to ensure all partners are clear on the respective roles and responsibilities of all participants in this framework.

Strategic actions. Develop a roles and responsibilities matrix for the representatives sitting on the steering committee. This document will be updated as representatives leave or join the steering committee. All steering committee members will get approval from their respective governance to ensure the ability to follow through with their identified roles and responsibilities. Steering committee members will be responsible for updating the partners if their roles and/or responsibilities change during the time of the partnership framework. The parties will ensure that 
corporate customers become familiar with the shared roles and responsibilities of the partnership framework.

Performance measures. At the one-day implementation workshop the steering committee will complete the roles and responsibilities matrix. Representatives where possible will ensure they have the mandate to make decisions for their respective governance. The roles, responsibilities, mandates and expectations will be reviewed annually.

\section{Management of Partnership}

Our definition. Develop and implement the logistics of how this partnership framework will be managed. This includes an understanding of: power-sharing, accountability, and responsibility. Successful empowerment within this partnership will depend primarily on the sharing or delegation of power. The collaborative process challenges the partners to be open minded to allow the partnership framework the opportunity to share authority and develop a mutual interest in understanding and appreciating each partner's culture and economic development mandate.

Strategic actions. When jointly reviewing economic opportunities or corporate customer requests, the steering committee will identify the management requirements and delegate a lead manager accordingly. Each partner will be transparent and honest about mutual concerns that have the potential to adversely impact the partnership. During the one-day workshop an administrative terms of reference will be developed which will address the following: rotating chair or appointed chair, how decision making occurs - consensus or majority, who is responsible for setting the agenda, taking minutes, and disseminating the information. As a way to monitor and evaluate actions and decisions of the nature of management, there will be allotted time at each regular meeting to assess such actions, discuss and adjust if necessary. Both partners will ensure their agency has the appropriate insurance liability, under economic partnership framework.

Performance measures. At the one-day implementation workshop the steering committee will complete the administrative terms of reference. At each of the quarterly meetings, time will be given to review and evaluate decisions and actions of how economic partnership management is progressing. The management of the partnership framework will be revisited regularly.

\section{Availability of Resources}

Our definition. The partners will share resources, as availability allows, that are in the best interest of the partnership. Leveraging each partner's resources, such as; monetary, human capital, expertise, specialized skills, and/or organizational culture, the partnership augments the opportunity and possibilities of the goals and objectives of the partnership framework. Sharing of resources inherently assumes sharing risk and sharing reward. Resources can also include access to each partner's contacts and networks within the economic and cultural landscape. Partners will be able to discover each other's abilities, capacity and performance.

Strategic actions. At the one-day workshop, each partner will provide current availability of resources. When an economic development venture has been agreed upon, partners will identify the required resources needed for success. From this list the partners will identify what resources they can, or cannot contribute. Through this process, the partners may identify the level of support they are able to contribute at any given time. For example, they may be able to support independent submissions, support joint submissions, as well as identify where they would not be able to support each other. This support can be in the way of: letters of support, resources shared and developing further relationships with third parties. Steering committee members will ensure an efficient approval process for shared resources, with their respective governance. Invite partners to information sessions, workshops, training, etc. that share knowledge and assist with business and resource capacity.

Performance measures. The annual report of each partner will identify what resources were shared, and what the results of this pooling of resources were. Partners will be invited to workshops, training, forums, etc. at a minimum of three (3) times a year, by each partner. At the one-day workshop members will have a good understanding what each partner resources are, and how they can, or cannot, be used to support this partnership framework. 


\section{Ensure Shared Value}

Our definition. This partnership framework will have a solid sense of shared value that is communicated and supported by a clear understanding and ongoing commitment from the partners. This will delineate false expectations. 'Mutuality' is apparent when both partners have something to gain and contribute to the partnership. Values important to LTFN: connections, knowledge-base, economic capacity building, build capacity with IPG in regards to First Nation culture and economics in Northern British Columbia. Values important to IPG: understanding of LTFN economic growth goals, certainty of process and process outcome, and identifying opportunities for joint marketing. Each partner brings assets and skills that have the potential to create partnership synergy for a long-term business relationship.

Strategic actions. Understand and accept each partner's values and reasons for entering into the partnerships and what they are able to contribute. Invite each partner to opportunities that will facilitate learning and capacity building. When entering into an economic partnership venture together, clearly state what each would like to gain from the partnership and what each can contribute to the partnership. Job shadowing and/or mentoring opportunities will be offered to the partners when they arise, or when the partnership requires them in order to support shared value. Acknowledgment given to the proponents of the partnership when appropriate. Share each partner's context for economic development activities; discuss each other's corporate priorities in order to develop a strategic workplan that will guide the partnership.

Performance measures. At the one-day implementation workshop the steering committee will identify what each partner hopes to achieve through this relationship. The shared values will be reviewed annually.

\section{Understanding business sense, capacity and readiness}

Our definition. Capacity development requires that growth and education is a mutual process between the two partners. Partners must be aware, committed, and patient in human resource development and capacity building between partners. Where there is a weakness, in terms of business readiness, the partners need to support each proponent by way of knowledge, training, expertise and/or referral, when able.

Strategic actions. The partnership has to be committed to assisting in the area of skill enhancement and management training including job shadowing or mentoring opportunities. Enroll in workshops/ forums/meetings that will assist the partners in areas identified as areas needed for improvement. Share information and/or applications to seminars or training opportunities and/or cultural events. Gap analysis to be completed for HR qualifications when economic opportunities are presented.

Performance measures. IPG to invite LTFN to three (3) public workshop/ training seminars within the year. LTFN to invite IPG representatives to three (3) workshop/training seminars within the year. At the one-day implementation workshop the steering committee will identify, where possible, the position of each partner in terms of business sense, capacity, and readiness.

\section{Separate politics from business}

Our definition. Two and three year elections for Chief and Council and local government respectively may result in short term economic development projects taking priority over long term economic strategies for the community. Focus on administration staff or development corporations, rather than elected officials to ensure implementation of long term business plans

Strategic actions. Work with the economic development department of each partner when establishing economic partnership opportunities. The steering committee members will be staff positions of the partner agencies to ensure continuity and consistency. Ensure economic development ventures are supported by the community-based priorities, as identified in the Comprehensive Community Plan (LTFN) and the Official Community Plan and Social Community Plan (City of Prince George) and IPG 3 year business plan. Identify governance issues/ concerns when negotiating an economic development partnership - identifying who should be involved, where approval needs to 
come from, and roles and responsibilities.

Performance measures. IPG will give LTFN their business transition plan to assist with developing an impartial arm to economic development from its governing systems. The Steering committee members representing the partnership are staff positions and not elected officials.

\section{Long term vision with community members}

Our definition. The community must see the partnership in a positive light; one that will bring economic benefits to the community and increase their standard of living without sacrificing their cultural values. Has to be a vision for the future. It is imperative for the Communities to develop their own long-term vision, one that is developed by the majority of members from the community. Inform and educate the membership on the potential projects - allow for feedback, input and questions.

Strategic actions. LTFN to develop their own long-term comprehensive community plan with members of their community. When an economic partnership venture is decided, ensure it fits within the partner's community plans. Obtain community members input through a community meeting and discuss the project with the membership where appropriate. Develop a process where the community is kept informed of the project and the status of it, especially if there are employment or training opportunities. This may be by way of the local community newsletters. Utilize the partners' website to offer links to economic partnership projects. Offer a blog, or feedback loop to allow community members to voice their concerns or ask questions.

Performance measures. LTFN is to discuss the framework with members before one-day workshop to obtain input and finalized mandate. IPG is to discuss framework with Board and City administration before one-day workshop to obtain feedback and finalize mandate.

\section{CONCLUSION}

The objective of this project was to develop an economic partnership framework between the LTFN and IPG which would engage each other in developing a strong, positive economic working relationship. The objective was accomplished by collaboratively developing the economic partnership framework. This began the journey of building a strong, engaged and sustainable working relationship between LTFN and IPG.

Although the factors used to establish the framework are likely applicable to any corporate - First Nations partnership, the results of this project as reported here are unique to the LTFN and IPG. Each First Nations band and corporate partner has unique characteristics that have to be accounted for in the development of an economic framework if the partnership is to be successful. This paper can serve as a guide to that development but cannot be used to create the partnership. Each party must progress through the same process that resulted in the development of this framework.

\section{AUTHOR INFORMATION}

Franca Petrucci works for the Northern Health Authority and has spent the last two decades working with at-risk populations in the Yukon and Northern BC. She brings experience in provincial, federal, municipal and First Nations levels in areas such as: youth entrepreneurship, employment infrastructures for at-risk populations, community capacity building, health services and the corrections system.

Rick Tallman is an Associate Professor at the University of Northern British Columbia. He teaches and conducts research primarily in the field of Organizational Behaviour. His interests encompass leadership, psychological contracts, workplace environments and healthcare management issues. 


\section{REFERENCES}

1. Anderson, Robert B. (1997). Corporate/Indigenous Partnerships in Economic Development: The First Nations in Canada." World Development, 25, 1483-1503.

2. Armstrong, Jim, \& Lenihan, Donald G. (1999). From Controlling to Collaborating: When Governments Want to be Partners: A Report on the Collaborative Partnerships Project. New Directions, 3. Toronto, ON: Institute of the Public Administration of Canada.

3. Brinkerhoff, Jennifer M. (2002). Government - Nonprofit Partnership: A Defining Framework. Public Administration and Development, 22, 19-30.

4. British Columbia Ministry of Economic Development. (2007). Best Practices Guide: Creating Resort Partnerships with First Nations, Volume 3. Victoria, BC: Author.

5. Curry, John, Donker, Han, \& Krehbiel, Richard. (2009). Development corporations in aboriginal communities: the Canadian experience. Journal of Developmental Entrepreneurship, 14(1), 1-19.

6. Davies, Jocelyn. (2007). Walking together, working together: Aboriginal research partnerships. Retrieved October 24, 2008 from www.desertknowledgecrc.com.au/publications/downloads/DKCRC-Report-26Aboriginal-Research-partnerships.pdf

7. Hailey, John. (2000). NGO Partners: The Characteristics of Effective Development Partnerships. In Stephen Osborne (Ed.) Public-Private Partnerships: Theory and Practice in International Perspective (pp 311-323). London: Routledge.

8. Hickey, Clifford G. \& Nelson, Mark. (2005). Partnership Between First Nations and the Forest Sector: A National Survey. Edmonton, AB: Sustainable Forest Management Network.

9. Huxham, Chris, \& Vangen, Siv. (2000). What makes partnerships work?. In Stephen Osborne (Ed.), Public-Private Partnerships: Theory and Practice in International Perspective (pp 293-311). London: Routledge.

10. Kernaghan, Kenneth. (1993). Partnership and public administration: conceptual and practical considerations. Canadian Public Administration,_36, 57-77.

11. Lichfield, Dalia (1998). Measuring The Success Of Partnership Endeavour. In N.Walzer and D. Jacobs (Eds.) Public Private Partnerships for Local Economic Development, Westport, CT: Praeger.

12. McQuaid, Ronald W. (2000). The theory of partnerships: Why have partnerships? In Stephen Osborne (Ed.), Public-Private Partnerships: Theory and Practice in International Perspective (pp 9-35). London: Routledge.

13. Parker, Martha. (1999). Partnerships: Profits and Not-for-Profits Together. Edmonton, Alberta: Muttart Foundation.

14. Rodal, Alti \& Mulder, Nick. (1993). Partnerships, devolution and power-sharing: issues and implications for management. Optimum, 24(3), 27-48.

15. Shanks, Gordon. (2005). Economic Development in First Nations: An Overview of Current Issues. Ottawa ON: Public Policy Forum.

16. Whyte, Laureen. (2006). Making the Grade: a Guide to Success for Corporate - Aboriginal Initiatives ( $2^{\text {nd }}$ ed.). Vancouver, BC: Industry Council for Aboriginal Business.

17. Wright, David, \& Rodal, Alti. (1993). Promoting Partnerships. Optimum, 24(3), 64-72. 
Journal of Business \& Economics Research-March, 2011 Volume 9, Number 3 NOTES 